\title{
Swarm Intelligence for Frequency Management in Smart Grids
}

\author{
Jose EVORA $^{1}$, Jose Juan HERNANDEZ ${ }^{1}$, Mario HERNANDEZ ${ }^{1}$, \\ Gintautas DZEMYDA ${ }^{2}$, Olga KURASOVA ${ }^{2 *}$, Enrique KREMERS ${ }^{3}$ \\ ${ }^{1}$ Universidad de Las Palmas de Gran Canaria \\ Edificio Central del Parque Científico y Tecnológico \\ Campus Universitario de Tafira, 35017 Las Palmas de GC, Spain \\ ${ }^{2}$ Institute of Informatics and Mathematics, Vilnius University \\ Akademijos 4, LT-08663 Vilnius, Lithuania \\ ${ }^{3}$ EIFER European Institute for Energy Research (KIT \& EDF) \\ Emmy Noether Str. 11, 76131 Karlsruhe, Germany \\ e-mail:jose.evora@siani.es,josejuanhernandez@siani.es,mhernandez@siani.es, \\ gintautas.dzemyda@mii.vu.lt,olga.kurasova@mii.vu.lt,enrique.enrique.kremers@eifer.org
}

Received: December 2014; accepted: August 2015

\begin{abstract}
A secure and high-quality operation of power grids requires frequency to be managed to keep it stable around a reference value. The deviation of the frequency from this reference value is caused by the imbalance between the active power produced and consumed. In the Smart Grid paradigm, the balance can be achieved by adjusting the demand to the production constraints, instead of the other way round. In this paper, an swarm intelligence-based approach for frequency management is proposed. It is grounded on the idea that a swarm is composed of decentralised individual agents (particles) and that each of them interacts with other ones via a shared environment. Three swarm intelligence-based policies ensure a decentralised frequency management in the smart power grid, where agents of swarm are making decisions and acting on the demand side. Policies differ in behaviour function of agents. Finally, these policies are evaluated and compared using indicators that point out their advantages.
\end{abstract}

Key words: swarm intelligence, multi-agent system, behaviour function, energy system, demand side management, smart grid, resilience, frequency management.

\section{Introduction}

Achieving stability and improving resilience are important concerns in power grids which mainly involve frequency control. The grid frequency in the European Continental Grid has a nominal value of $50 \mathrm{~Hz}$ and is related to the speed of rotation of production generators. Imbalances between electricity production and consumption lead to deviations from this nominal value.

Any significant deviations from this nominal value must be controlled. Traditionally, these deviations have been controlled by dispatching production units according to the

\footnotetext{
*Corresponding author.
} 
consumption of electricity. This means that consumption has to be predicted in order to manage production. However, information technologies (IT) are enabling new ways of managing these imbalances by shedding loads depending on grid conditions. This ability makes it possible to balance the grid on the demand side and, in addition, to act on the production side. This is known as Demand Side Management, a core concept of the Smart Grids ${ }^{1,2}$ (Wang et al., 2012). The control of the demand side provides flexibility to integrate renewable energy sources (Moura and deAlmeida, 2011), distributed generation and storage.

In the previous grid management paradigm, few production units were necessary to control the grid. Under a new paradigm, every load could be considered as a controllable unit. Therefore, many units may be participating in controlling the frequency, as it is made with electric vehicles in Zhong et al. (2014). Furthermore, it is more than just the number of units that have to be taken into account, it is also the structure of the control system. Traditionally, production units were controlled by a central operator, responsible for scheduling production units according to the consumption. In Smart Grids, since many units can make local decisions, a decentralised control system should be watching over the system stability.

From the point of view of artificial intelligence, these units can be considered as agents. These agents are able to perceive the environmental conditions and make local decisions that contribute to a global objective, in this case, grid stability. Agents can act following simple rules to decide whether to decrease or increase electricity consumption.

In this paper, several policies based on swarm intelligence for management grid frequency are presented. These policies are implemented as agent swarms where each agent acts depending on its perception of the environment. The behaviour that emerges from these local behaviours should improve the global objective. These policies are also evaluated using indicators that point out their advantages.

The remainder of this paper is organised as follows. First, the swarm intelligence and resilience engineering constructs are reviewed. Then, design of behaviour of swarm agents for frequency management is proposed and evaluated. Finally, conclusions are discussed.

\section{Swarm Intelligence}

Artificial intelligence methods are under wide development in various directions. These developments cover artificial neural networks (Haykin, 2009; Schmidhuber, 2011; Dzemyda et al., 2007, 2013; Medvedev et al., 2011; Ivanikovas et al., 2011), evolutionary computation (Simon, 2013; Eiben and Smith, 2003; Filatovas et al., 2015; Vaira and Kurasova, 2013, 2014), fuzzy set theory (Ross, 2010), artificial immune systems (Al-Enezi et al., 2010), etc. Some taxonomy of nature inspired artificial intelligence is given in Goel et al. (2012). One of widely used nature inspired artificial intelligence techniques is swarm intelligence. As noted in Zhang et al. (2013), the areas of application of swarm intelligence

\footnotetext{
${ }^{1}$ http://www.smartgrids.eu.

${ }^{2} \mathrm{http} / / /$ energy.gov/oe/services/technology-development/smart-grid.
} 
are library materials acquisition, communications, medical dataset classification, dynamic control, heating system planning, moving objects tracking, and prediction. Thus, swarm intelligence can be applied to a variety of fields in fundamental research, engineering, industries, and social sciences.

The concept of Swarm Intelligence (SI) was introduced in Beni and Wang (1993). It is the emergent collective intelligence of groups of simple agents (or particles) acting almost independently. The originators were interested in how robots programmed with simplistic behaviours may output intelligence as the result of the emergence coming from their collective behaviour. Systems of non-intelligent robots exhibiting collectively intelligent behaviour evident in the ability to produce unpredictably specific (i.e. not in a statistical sense) ordered patterns of matter in the external environment (Beni and Wang, 1993).

Thus, SI systems are composed of autonomous units called agents or particles. These units behave according to simple rules related to interaction mechanisms between themselves or actions on the environment. Applying simple local rules, a global system behaviour emerges. However, this emergent behaviour is not predictable. Basically swarm intelligent systems are unpredictable for their definition of unpredictably (which is thorough) and they produce results that are improbable so are in some way surprising or unexpected (Beni and Wang, 1993).

Since intelligent behaviour should emerge from collaboration rather than from individual abilities, each agent should:

- be designed to be very simple,

- have a limited knowledge of the environment, which they should be able to modify only locally,

- be designed according to the reactive paradigm (Martino et al., 2006).

SI allows to explore collective (or distributed) problem solving without centralised control. In SI systems we can observe several properties that are characteristics of living systems, i.e. insect colonies (Bonabeau and Meyer, 2001): the colony can respond to internal perturbations and external challenges (flexibility); tasks are completed even if some individuals fail (robustness); there is no central controller in the colony (decentralisation); paths to solutions are emergent rather than predefined (self-organisation).

Thus, SI systems are self-organised systems. They require interactions between its composing agents. Two types of interaction (direct and indirect) exist. Direct interaction occurs when there is an explicit information exchange between agents. Indirect interaction occurs when one agent modifies the environment and other responds to the new environment at a later time. This interaction is called stigmergy. It is one of the most important theoretical concept of swarm intelligence (Cagigal, 2014; Garnier et al., 2007). Moreover, the concept of stigmergy is a feature distinguishing SI from other multi-agent systems, where the agents communicate directly between each other. In the SI paradigm the agents communicate by modifying a shared environment (Martino et al., 2006).

Resuming the discussion above, the peculiarities of SI system are as follows:

- it is composed of a collective of relatively homogeneous unintelligent agents with limited individual capabilities, 
- the behaviour of the collective of agents self-organises so that it exhibits an emergent intelligent behaviour,

- the interactions among the agents are based on simple rules exploiting local information that the agents exchange directly or via the environment (stigmergy),

- in case of stigmergy, indirect agent interaction modifies the environment and such a modification serves as external memory,

- the collective intelligence of the swarm is emergent observable effect that cannot be defined explicitly.

There are several approaches to represent SI systems. Most of them are inspired by natural living systems as, for example, ant colonies and bee or bird swarms. The pheromonetrail following behaviour of ants has inspired Ant Colony Optimisation (ACO) (Dorigo et al., 1991; Dorigo, 1992; Colorni et al., 1994). Flocking and swarming behaviour has inspired Particle Swarm Optimisation (PSO) (Ahmed and Glasgow, 2012).

SI has been previously used to control different aspects in Power Grids. In Yoshida et al. (2000), the control of reactive power and voltage is made using particle swarm optimisation. In Cao (2004), the power grid is balanced through a collection of local interactions using ant colony optimisation. An ecosystem of intelligent, autonomous and cooperative ants is presented in Salehi and Deldari (2006). These ants make decisions when the system is unbalanced. An improved version of the ant colony optimisation is used in Sim and Sun (2003). In this version, multiple colonies are used for optimising the performance of a congested network by routing energy via several alternative paths.

In this research, SI is used to address the problem of grid balance. This problem is dealt with smart devices that are able to monitor the grid state and act in accordance. Here agents of swarm act in a decentralised and indirect manner. That is to say, they do not cooperate directly due to the fact that power grids are not yet providing support for the communication. Moreover, the agents are not communicated each with other directly, but each agent affects and changes environment (Power Grid) and the other agents operate according to the changed environment. As a result, the challenge that is addressed in this research is the balance of the grid using decentralised agents which make decisions considering only the state of the grid.

\section{Resilience Engineering}

Resilience is defined as the capacity of a system to absorb disturbance and reorganise while undergoing change so as to still retain essentially the same function, structure, identity, and feedback (Walker et al., 2004).

In complex systems, resilience may be considered an emergent property (Berkes et al., 2003). It cannot be predicted simply by examining the system's individual components. Since many complex systems are hierarchic, i.e. each subsystem is included in a larger system (Allen and Starr, 1982), prediction is even more difficult. Phenomena at each level of the scale tend to have their own emergent properties, and different levels may be coupled through feedback relationships (Gunderson, 2001). 
Complex systems are stated around one of several possible attractors. When small changes appear, a system normally tends to be stable and maintain its current state around one of these attractors (Berkes et al., 2003). At a certain level of change, the system can flip to a new attractor. Such a flip may occur very rapidly and even catastrophically and the new attractor is rarely predictable.

The concept of Engineering Resilience (Holling, 1996) focuses on how to achieve resistance to disturbance and increase the speed of return to equilibrium after the system is disturbed (Pimm et al., 1991). In the case of engineered complex systems, components must be designed to monitor and evaluate the state of the system. Based on this evaluation, they should make decisions that maintain system-operating conditions within safe boundaries. Monitoring the system state should lead to local actions to achieve an adaptive capacity as the system changes.

Resilience is a major design concern for power grids, large electrical systems that produce, transport, distribute and supply electricity. Stable power grids supply households with electricity at $220 \mathrm{~V}$ and at a frequency of $50 \mathrm{~Hz}$. In order to achieve this, there should be a steady balance between production and consumption. Power grids should be resilient to disturbances in order to avoid power outages and improve the service for the public. The costs of outages include spoiled inventory, delayed production and damage to infrastructure. Investment in grid modernisation and resilience will mitigate these costs over time (Amin, 2001).

\section{Design of Behaviour of Swarm Agents for Frequency Management}

The aim of this research is to design and optimise behaviour of swarm agents for frequency management. The behaviour is defined by some function. Three different behaviour functions are proposed and discussed in this section. These three functions lead to three autonomous load shedding policies of smart appliances that allow to manage grid frequency in order to keep it stable around a reference value.

Since the grid frequency can be measured from any power outlet, a smart appliance connected to the grid could know the current imbalance on the grid. This means that it is possible to design a smart appliance that can disconnect or reconnect itself to the grid in order to improve the stability.

Based on the grid frequency measure, individually and locally, each appliance decides whether to stop consuming or to support the reserve mechanisms of the power grid, and thus increase the stability of the system. When frequency reaches normal operating margins, appliances decide to restart working in their normal mode. This mechanism seems to work well in stabilising the system after major events like the breakdown of a production unit (Kremers et al., 2013a, 2013b). A simulation model of a domestic refrigerator (micro-level) is coupled with a simplified model of an electrical energy system (macrolevel). In the model, Smart refrigerators are present in numerous households as examples of appliances which are monitoring and controlling the consumption. However, the studies also detected that, under certain circumstances, increasing the number of controlled 


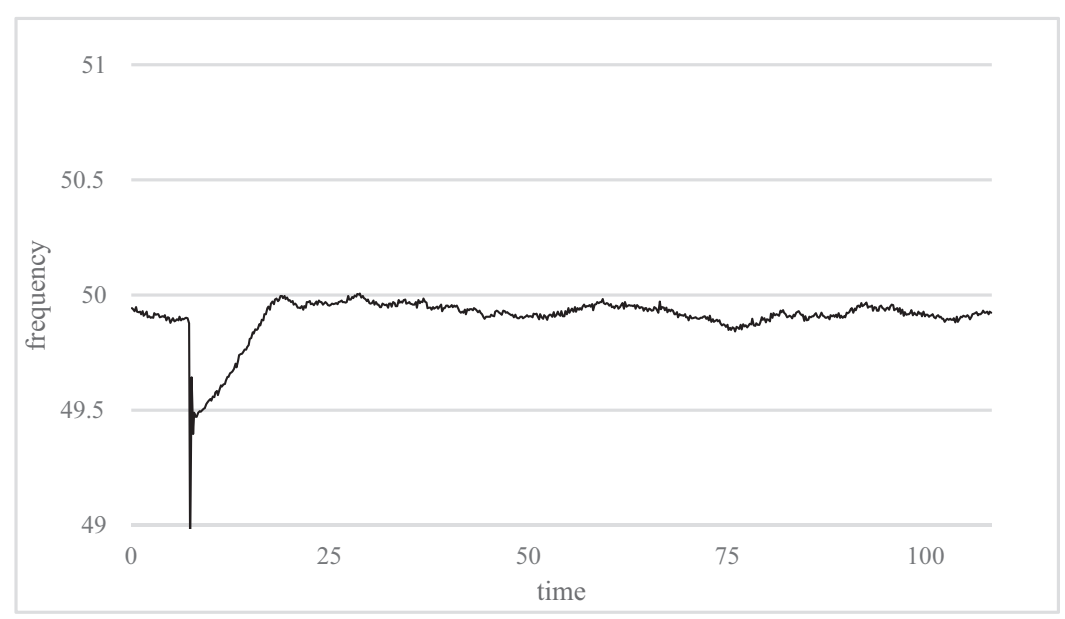

Fig. 1. Frequency reaction facing a generation unit failure (base case).

refrigerators, non-desired effects like oscillations occurred. The model allows for a first analysis by quantifying the risk of such an event.

In term of swarm intelligence, a set of the refrigerators composes a swarm, each refrigerator is an agent (or particle) of this swarm. By defining behaviour function of the agents, we describe the possible reaction of refrigerators to changes of frequency, i.e., policies that may be autonomously executed in each refrigerator. These policies make smart refrigerators react according to significant imbalances locally detected through the frequency.

Since it is a collective behaviour, we expect to have global emergent behaviours as a result of dealing with the frequency based on these simplistic local policies. The resultant implementation is a swarm intelligence system in which frequency management is decentralised.

The scenario that is used for developing and evaluating the policies consists of 4000 households with refrigerators. 4000 households is a representative sample that can be easily simulated. Households have been set with an external temperature adjusted to a uniform distribution between $20-30^{\circ} .75 \%$ of these refrigerators are smart appliances, that is to say, controllable. This means, 3000 refrigerators will be monitoring the grid frequency and making decisions on their own consumption.

The goal to find the optimal behaviour function of agents of the swarm is achieved by simulation that implements a generation unit failure. This failure causes an abrupt drop in the frequency from $50 \mathrm{~Hz}$ making the power grid unstable. This drop is due to the production fall while consumption remains the same after the failure. In Fig. 1, the effect of this failure in the frequency is presented. This is the base case in which there are no refrigerators that could disconnect themselves to adjust the demand. This case may serve as the reference point in developing the behaviour functions.

However, the hypothesis is that the demand side may help to improve frequency recovery. If consumption were able to follow this production fall, frequency could recover 


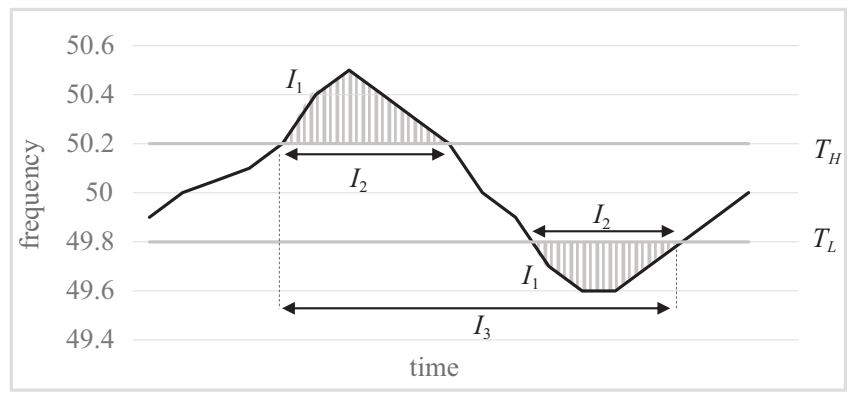

Fig. 2. Indicators that are used to evaluate policies.

the nominal value at $50 \mathrm{~Hz}$ faster. This can be done by using smart refrigerators that are able to adapt their consumption disconnecting/reconnecting when frequency drops.

In the next subsections, different demand side policies based on different behaviour functions of agents are presented and experimentally evaluated. The faster they recover this production fall, the better the policy is.

\subsection{Performance Indicators}

To evaluate the performance of behaviour functions of swarm agents, three indicators have been defined. These indicators are aimed at obtaining a quantitative comparison among the different behaviour functions. In Fig. 2, indicators named as $I_{i}$ show which information is used to calculated them. $T_{H}$ and $T_{L}$ are thresholds that delimit what we consider the normal operating values of the frequency. We consider that the system becomes unstable whenever the frequency surpasses these thresholds. The next list shows how these indicators are calculated:

- $I_{1}$ : is the "total instability". This is calculated as the area of the frequency curve over or under the thresholds. It is the pattern filled area in Fig. 2.

- $I_{2}$ : is the "instability length". It is calculated as the average duration of unstable periods.

- $I_{3}$ : is the "unstable time". This is the total duration of unstable periods.

\subsection{Policy \#1}

Let $f(t) \in\{0,1\}$ is a behaviour function that describing a changing state of refrigerator (agent) operation. $t$ is a time moment when the state of agent changes. $f(t)=0$ indicates that the refrigerator is switched off, while $f(t)=1$ indicates that the refrigerator is switched on. A function $\phi(t)$ measures power frequency in a time moment $t$. In the paper, three policies for managing grid frequency are examined. Each policy consists in monitoring the power grid frequency and reacting according to detected events. One policy differs from others in rules of disconnection and reconnection of refrigerators, i.e. in function $f(t)$. 


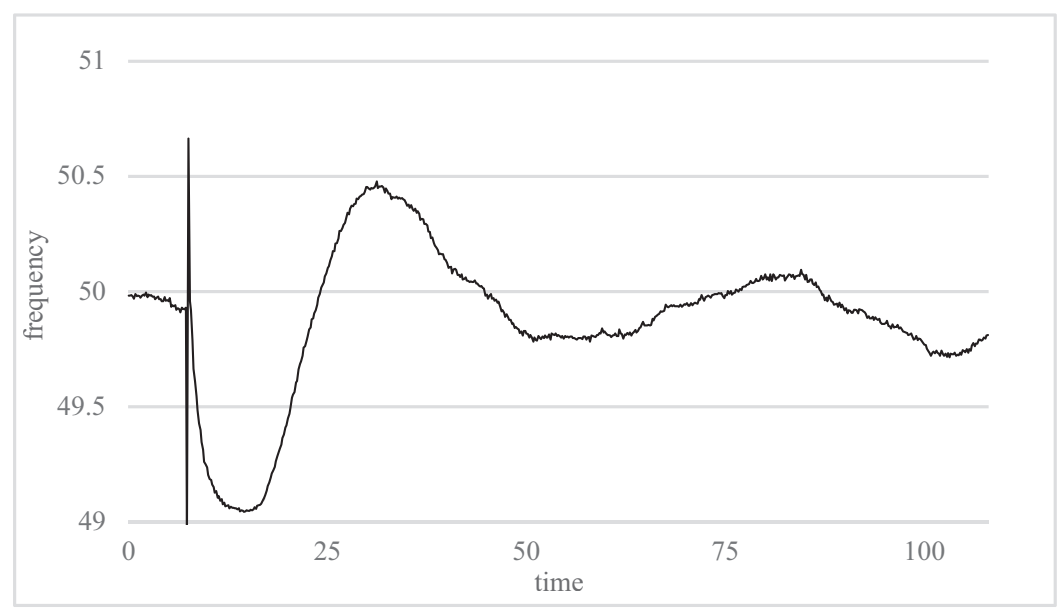

Fig. 3. Frequency reaction facing the failure using Policy $\# 1 v=49 \mathrm{~Hz}$.

The first policy considers an "event" to be whenever the monitored frequency $\phi(t)$ is lower than a threshold $v$. If this occurs, the policy switches off the refrigerator stopping its consumption instantaneously. However, it keeps monitoring in order to reestablish the refrigerator's operation as soon as the frequency is higher than $v$. This policy is the same than the one used in Viejo et al. (2013), Kremers et al. (2013b). Here, the behaviour function $f(t)$ of agents is expressed by Eq. (1).

$$
f(t)= \begin{cases}0, & \text { if }(f(t)=1 \text { and } \phi(t)<v), \\ 1, & \text { if }(f(t)=0 \text { and } \phi(t) \geqslant v) .\end{cases}
$$

In order to test this policy, a simulation was performed in which all controllable refrigerators of the previously described scenario were programmed with the policy. In this simulation $v=49 \mathrm{~Hz}$. Figure 3 presents the results obtained on the frequency. As it can be observed there is a first big oscillation followed by smaller ones. It can be considered that the system reaches stability after 100 minutes. In comparison to the base situation in which no refrigerator is being disconnected, this policy clearly produces worse results than not reacting to the event.

\subsection{Policy \#2}

The second policy is based on the same idea, but the way in which it reacts changes, since the policy keeps monitoring the frequency grid. Whenever the frequency $\phi(t)$ is lower than a threshold $v$, it makes a decision. When this event happens, each refrigerator will wait a variable amount of time $\xi_{1}$ distributed uniformly. This amount represents the sleep time before making the decision. Once this time is over, the refrigerator will check the frequency state and act accordingly. If the frequency is lower, the refrigerator will stop consuming, if not, it will keep working in its normal operation mode (Eq. (2)). The idea 


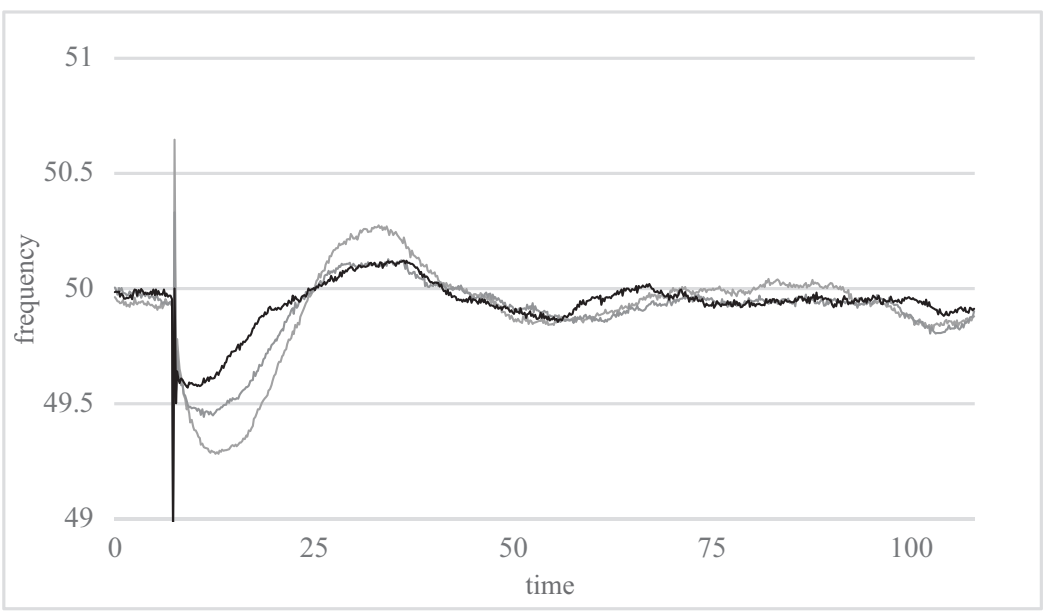

Fig. 4. Frequency reaction facing the failure using Policy $\# 2 v=49 \mathrm{~Hz}, \xi_{1} \in[0,10]$ in light grey, $\xi_{1} \in[0,20]$ in dark grey, $\xi_{1} \in[0,30]$ in black.

behind this policy is to avoid that every refrigerator reacts at the same time to the frequency event, as this provokes a higher impact on the power grid (Kremers et al., 2013a).

$$
f(t)= \begin{cases}0, & \text { if }\left(f(t)=1 \text { and } \phi(t)<v \text { and } \phi\left(t-\xi_{1}\right)<v\right) \\ 1, & \text { if }(f(t)=0 \text { and } \phi(t) \geqslant v) .\end{cases}
$$

In order to test this policy, three simulations were performed with $v=49 \mathrm{~Hz}$, and different values of $\xi_{1}$ : in the first one, the range is between 0 and 10 seconds $\left(\xi_{1} \in[0,10]\right)$; the second, between 0 and $20\left(\xi_{1} \in[0,20]\right)$; and the third onwards between 0 and 30 seconds $\left(\xi_{1} \in[0,30]\right)$.

In Fig. 4, frequency curves are presented for these three simulations. It can be observed that the longer the range is, the faster the frequency recovers its normal operation mode. Furthermore, oscillations are also lighter with longer ranges. This policy is clearly an improvement on the first one but it is still worse than the base case.

\subsection{Policy \#3}

Following the idea of the second policy, in the third policy a second delay is established. Thus, this policy uses two different delays: the disconnection delay and the reconnection delay. In the previous policy, an oscillatory effect can be observed. This effect happens since all refrigerators are reconnected at the same time (when frequency recovers). This means that all refrigerators have a synchronised behaviour. Meaning, all of them consume and stop consuming at the same time. This synchronisation effect takes time to disappear.

Thus, this third policy does not only apply the same delay in the disconnection, but another different one in the reconnection. As before, when a frequency event is observed by the refrigerator, it calculates a delay between 0 and a parametrised number $\xi_{1}$. When 


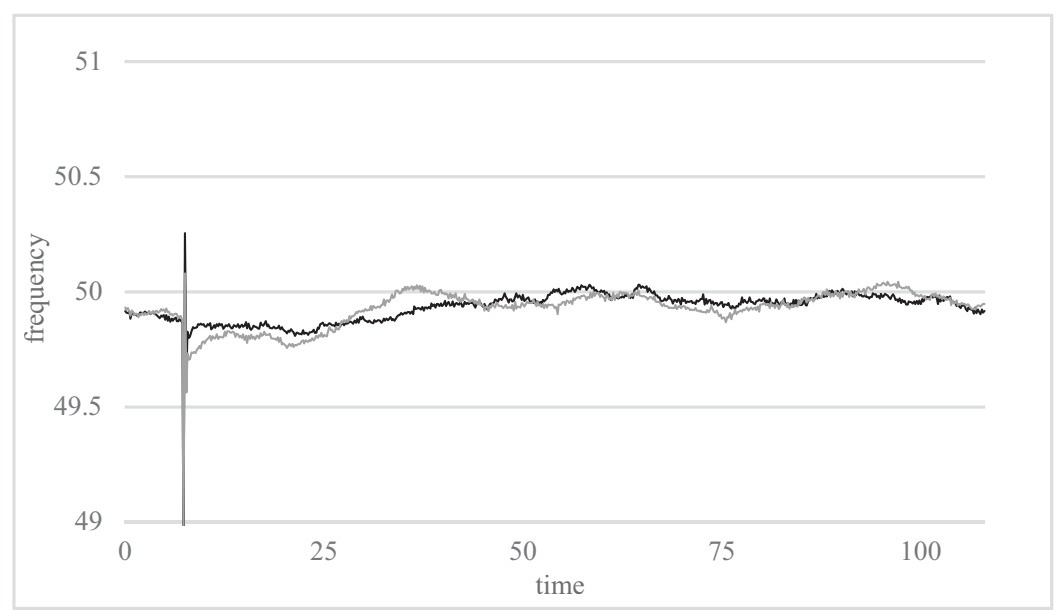

Fig. 5. Frequency reaction facing the failure using Policy \#3 $v=49 \mathrm{~Hz}, \delta=0.8 \mathrm{~Hz}, \xi_{1} \in[0,60]$ and $\xi_{2} \in[0,900]$ in light grey, $\xi_{1} \in[0,40]$ and $\xi_{2} \in[0,600]$ in black.

that time is reached, frequency is checked again in order to decide whether it is necessary to stop consuming or not.

The second delay works in the same way. This is, if refrigerators are disconnected and the frequency reaches a reconnection threshold $v+\delta$, a delay is calculated between 0 and a second parametrised number $\xi_{2}$ following a uniform distribution. When the delay time is reached, the frequency is checked again to see if it is still over $v+\delta$. In the case it is not, the refrigerator will wait until the frequency reaches that level and the delay will be recalculated again (Eq. (3)).

In order to test this policy, two simulations were performed with $v=49 \mathrm{~Hz}, \delta=$ $0.8 \mathrm{~Hz}$, and different values of $\xi_{1}$ and $\xi_{2}$ : in the first one $\xi_{1} \in[0,60], \xi_{2} \in[0,900]$; and in the second one $\xi_{1} \in[0,40], \xi_{2} \in[0,600]$.

$$
f(t)= \begin{cases}0, & \text { if }\left(f(t)=1 \text { and } \phi(t)<v \text { and } \phi\left(t-\xi_{1}\right)<v\right) \\ 1, & \text { if }\left(f(t)=0 \text { and } \phi(t) \geqslant v+\delta \text { and } \phi\left(t-\xi_{2}\right) \geqslant v+\delta\right) .\end{cases}
$$

In Fig. 5, two different configurations of this policy are presented. As it can be seen, oscillatory effects have almost disappeared and frequency is stabilised in a short period of time. The first configuration seems to be better as frequency speeds up to a good level over the reconnection threshold $(v=49 \mathrm{~Hz}, \delta=0.8 \mathrm{~Hz}$ ). In this way, resilience is improved.

\subsection{Evaluation}

In this section, previous indicators $I_{1}, I_{2}$ and $I_{3}$ are used to evaluate the advantages of the different behaviour functions of swarm agents and the efficiency of policies. In Fig. 6, the indicators calculated for each policy are presented with respect to the values obtained for the base case. The height of the column is a difference between the value of indicator by 


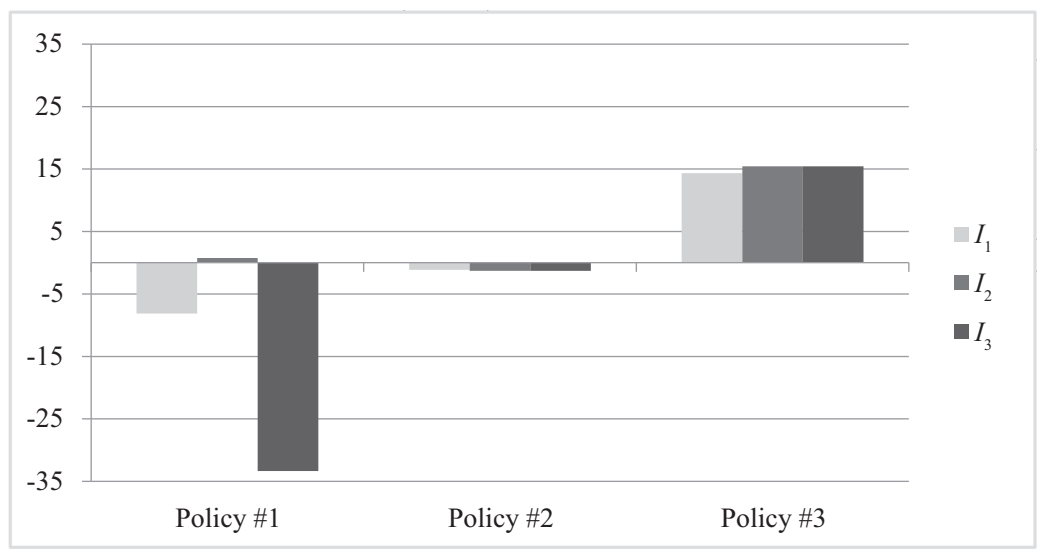

Fig. 6. Difference of policy indicator values using as reference the base case indicators.

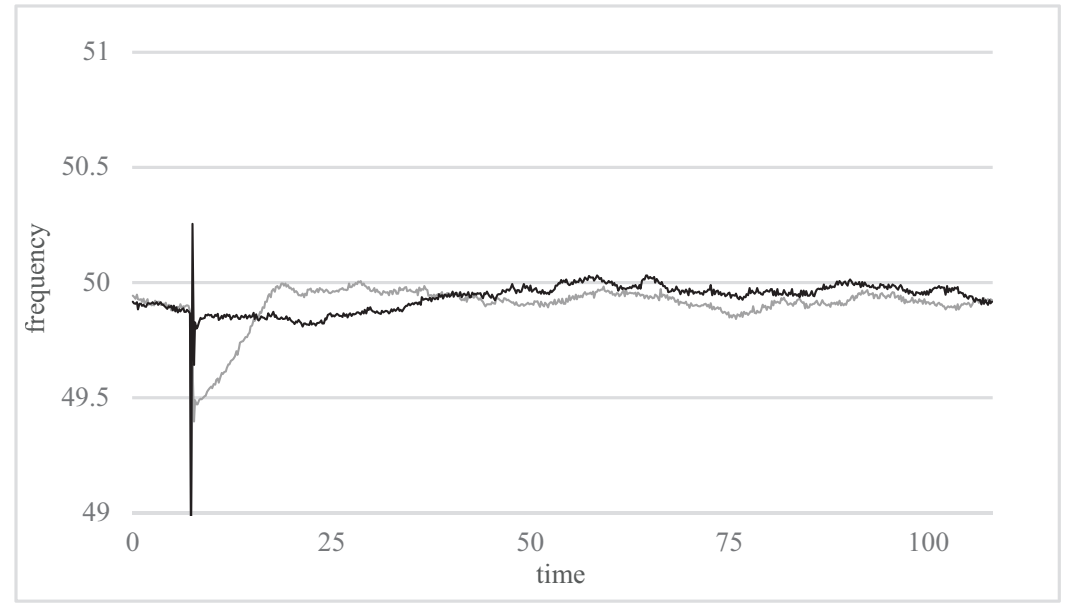

Fig. 7. Comparison between best policy (black) and base case (light grey) in which no refrigerator reacts to the frequency event.

some policy and the base case. In the cases of Policies \#2 and \#3, the best configuration has been considered only. As it can be observed, best results are obtained by Policy \#3 with almost no instability and the shortest total instability time.

In Fig. 7, the best solution of the policies presented against the base case is visually presented. On the one hand, no refrigerator is used improve the resilience (base case). On the other hand, the third policy uses refrigerators to improve the resilience using the configuration where $\xi_{1} \in[0,40]$ and $\xi_{2} \in[0,600]$, as parametrisation. It can be observed that this policy produces more stable results at the beginning of the frequency event. By means of this third policy, a good operating frequency level is achieved faster than in the base case. 


\section{Conclusions}

In this paper, a swarm intelligence-based approach for frequency management has been proposed. It is grounded on the idea that a swarm is composed of decentralised individual agents or particles and that each agent interacts with other agents via a shared environment.

A hypothesis of decentralised control for the frequency management in power grids has been proposed and tested. Many smart devices on the demand side are observing the grid frequency and individually acting by disconnecting or reconnecting themselves to the grid.

From the point of view of the system behaviour, this decentralised control was analysed as a swarm intelligent system. The emergent behaviour that comes out from individual behaviour should exhibit stability and resilience improvement. The engineering of these two properties is complex since synchronised effects should be avoided when many agents coincide in the decisions they make.

Three swarm intelligence-based policies have been proposed seeking to optimise the decentralised frequency control in smart power grid, where agents of swarm are making decisions and acting on the demand side. Policies differ in behaviour functions of agents. Finally, these policies are evaluated and compared using indicators that point out their efficiency.

The wide experimental investigation shows that small variations in the behaviour of devices involve meaningful effects in the grid stability and resilience. It has been observed that properly organised agent behaviour may improve the base case in which there are no smart devices that help to stabilise the system.

It has been observed that deterministic policies (base case and Policy \#1) involve synchronisation among devices and accumulative effects that cause undesired instabilities. However, policies that implement random disconnection and reconnection times (Policy \#3) may give better results than deterministic ones.

The research results allow to conclude that the optimal solutions of frequency management in smart power grids may be found by developing new swarm intelligence-based policies with various modes of collective behaviour of agents.

Acknowledgments. This work has been partially supported by: European Regional Development Fund (ERDF/FEDER), and Agencia Canaria de Investigación, Innovación y Sociedad de la Información (ACIISI) of Canary Islands Autonomous Government through the project whose reference is SolSub200801000137, and also through the ACIISI PhD grant funding to José Évora with reference TESIS20100095.

\section{References}

Ahmed, H., Glasgow, J. (2012). Swarm intelligence: concepts, models and applications. School of Computing, Queens University technical report.

Al-Enezi, J., Abbod, M., Alsharhan, S. (2010). Artificial immune systems models, algorithms and applications. International Journal of Research and Reviews in Applied Sciences, 3(2), 118-131. 
Allen, T.F., Starr, T.B. (1982). Hierarchy: Perspectives for Ecological Complexity. University of Chicago Press, Chicago.

Amin, M. (2001). Toward self-healing energy infrastructure systems. Computer Applications in Power, IEEE, 14(1), 20-28.

Beni, G., Wang, J. (1993). Swarm intelligence in cellular robotic systems. In: Robots and Biological Systems: Towards a New Bionics? Springer, Berlin, pp. 703-712.

Berkes, F., Colding, J., Folke, C. (2003). Navigating Social-Ecological Systems: Building Resilience for Complexity and Change. Cambridge University Press, Cambridge.

Bonabeau, E., Meyer, C. (2001). Swarm intelligence: a whole new way to think about business. Harvard Business Review, 79(5), 106-114.

Cagigal, M.C. (2014). A swarm intelligence approach based on coupled oscillators: an application in demand side management with photovoltaic distributed generation. PhD. thesis, Universidad Politécnica de Madrid, Spain.

Cao, J. (2004). Self-organizing agents for grid load balancing. In: Proceedings of the 5th IEEE/ACM International Workshop on Grid Computing. IEEE Computer Society, Los Alamitos, pp. 388-395.

Colorni, A., Dorigo, M., Maniezzo, V., Trubian, M. (1994). Ant system for job-shop scheduling. Belgian Journal of Operations Research, Statistics and Computer Science, 34(1), 39-53.

Dorigo, M. (1992). Optimization, learning and natural algorithms. PhD thesis, Politecnico di Milano, Italy.

Dorigo, M., Maniezzo, V., Colorni, A., Maniezzo, V. (1991). Positive Feedback as a Search Strategy. Technical report 91-016, Politecnico di Milano, Italy.

Dzemyda, G., Kurasova, O., Medvedev, V. (2007). Dimension reduction and data visualization using neural networks. In: Maglogiannis, I., Karpouzis, K., Wallace, M., Soldatos, J. (Eds.), Emerging Artificial Intelligence Applications in Computer Engineering. Frontiers in Artificial Intelligence and Applications, Vol. 160. IOS Press, pp. 25-49.

Dzemyda, G., Kurasova, O., Žilinskas, J. (2013). Multidimensional Data Visualization: Methods and Applications. Springer, Berlin.

Eiben, A.E., Smith, J.E. (2003). Introduction to Evolutionary Computing. Springer Science \& Business Media.

Filatovas, E., Kurasova, O., Sindhya, K. (2015). Synchronous R-NSGA-II: an extended preference-based evolutionary algorithm for multi-objective optimization. Informatica, 26(1), 33-50.

Garnier, S., Gautrais, J., Theraulaz, G. (2007). The biological principles of swarm intelligence. Swarm Intelligence, 1(1), 3-31.

Goel, L., Gupta, D., Panchal, V.K., Abraham, A. (2012). Taxonomy of nature inspired computational intelligence: a remote sensing perspective. In: Fourth World Congress on Nature and Biologically Inspired Computing, NaBIC 2012, Mexico City, Mexico, November 5-9, 2012, pp. 200-206.

Gunderson, L.H. (2001). Panarchy: Understanding Transformations in Human and Natural Systems. Island Press, Washington.

Haykin, S.S. (2009). Neural Networks and Learning Machines, 3rd ed. Prentice-Hall, New York.

Holling, C. (1996). Engineering resilience versus ecological resilience. Foundations of Ecological Resilience, 51-66.

Ivanikovas, S., Dzemyda, G., Medvedev, V. (2008). Large datasets visualization with neural network using clustered training data. In: Atzeni, P., Čaplinskas, A., Jaakkola, H. (Eds.), Proceedings of 12th East-European Conference on Advances in Databases and Information Systems (ADBIS 2008). Lecture Notes in Computer Science, Vol. 5207. Springer, pp. 143-152.

Kremers, E., González deDurana, J.M., Barambones, O., Koch, A. (2013a). Towards complex system design and management in the engineering domain the smart grid challenge. Emergence: Complexity \& Organization, $15(2), 14-22$.

Kremers, E., Marı, J., Barambones, O., et al. (2013b). Emergent synchronisation properties of a refrigerator demand side management system. Applied Energy, 101, 709-717.

Martino, G.D.S., Cardillo, F.A., Starita, A. (2006). A new swarm intelligence coordination model inspired by collective prey retrieval and its application to image alignment. In: Runarsson, T.P., Beyer, H.G., Burke, E.K., Guervós, J.J.M., Whitley, L.D., Yao, X. (Eds.), PPSN. Lecture Notes in Computer Science, Vol. 4193.

Medvedev, V., Dzemyda, G., Kurasova, O., Marcinkevičius, V. (2011). Efficient data projection for visual analysis of large data sets using neural networks. Informatica, 22(4), 507-520.

Moura, P.S., deAlmeida, A.T. (2010). The role of demand-side management in the grid integration of wind power. Applied Energy, 87(8), 2581-2588. 
Pimm, S.L. (1991). The Balance of Nature?: Ecological Issues in the Conservation of Species and Communities. University of Chicago Press, Chicago.

Ross, T.J. (2010). Fuzzy logic with Engineering Applications, 3rd ed. John Wiley \& Sons, New York.

Salehi, M.A., Deldari, H. (2006). Grid load balancing using an echo system of intelligent ants. In: Parallel and Distributed Computing and Networks. pp. 47-52.

Schmidhuber, J. (2015). Deep learning in neural networks: an overview. Neural Networks, 61, 85-117.

Sim, K.M., Sun, W.H. (2003). Ant colony optimization for routing and load-balancing: survey and new directions. IEEE Transactions on Systems, Man and Cybernetics, Part A: Systems and Humans, 33(5), 560-572.

Simon, D. (2013). Evolutionary Optimization Algorithms: Biologically-Inspired and Population-Based Approaches to Computer Intelligence. John Wiley \& Sons, New York.

Vaira, G., Kurasova, O. (2013). Genetic algorithms and VRP: the behaviour of a crossover operator. Baltic Journal of Modern Computing, 1(3-4), 178-202.

Vaira, G., Kurasova, O. (2014). Genetic algorithm for VRP with constraints based on feasible insertion. Informatica, 25(1), 505-521.

Viejo, P., Kremers, E., Evora, J., Hernandez, J.J., Hernandez, M., Barambones, O., deDurana, J.G. (2013). Criticality in complex sociotechnical systems, an empirical approach. In: European Conference on Complex Systems 2013 (ECCS'13).

Walker, B., Holling, C.S., Carpenter, S.R., Kinzig, A. (2004). Resilience, adaptability and transformability in social-ecological systems. Ecology and Society, 9(2), 5.

Wang, J., Conejo, A.J., Wang, C., Yan, J. (2012). Smart grids, renewable energy integration, and climate change mitigation - future electric energy systems. Applied Energy, 96, 1-3.

Yoshida, H., Kawata, K., Fukuyama, Y., Takayama, S., Nakanishi, Y. (2000). A particle swarm optimization for reactive power and voltage control considering voltage security assessment. IEEE Transactions on Power Systems, 15(4), 1232-1239.

Zhang, Y., Agarwal, P., Bhatnagar, V., Balochian, S., Yan, J. (2013). Swarm Intelligence and Its Applications. The Scientific World Journal, 2013.

Zhong, J., He, L., Li, C., Cao, Y., Wang, J., Fang, B., Zeng, L., Xiao, G. (2014). Coordinated control for largescale EV charging facilities and energy storage devices participating in frequency regulation. Applied Energy, $123,253-262$ 
J. Evora was born in Spain in 1987. He received the BE, ME, and PhD degrees from Universidad de Las Palmas de Gran Canaria, Canary Islands, Spain. Currently, he is working in Monentia SL, Las Palmas de GC, Spain, a consultancy company that works deploying Smart City solutions in the R\&D department. Dr. Evora is a collaborator of the Institute SIANI that belongs to the Universidad de Las Palmas de Gran Canaria. His main areas of research interest are software engineering, modelling languages, model driven engineering, simulation and artificial intelligence.

J.J. Hernandez was born in Spain in 1968. He received the BE, ME, and PhD degrees from Universidad de Las Palmas de Gran Canaria, Canary Islands, Spain. Currently, he is professor in the faculty of Informatics in the Universidad de Las Palmas de Gran Canaria. Dr. Hernandez is a full-member of the Institute SIANI that belongs to the Universidad de Las Palmas de Gran Canaria. His main areas of research interest are software engineering, modelling languages, model driven engineering, simulation and artificial intelligence.

M. Hernandez holds a Ms degree in Electrical Engineering and a PhD in Computer Sciences. He is actually Full Professor in Computer Sciences and Artificial Intelligence in Computer Sciences School of the University of Las Palmas de Gran Canaria (ULPGC) and Fellow Researcher in the SIANI Institute. His research interests are Artificial Intelligence, Machine Learning and Pattern Recognition, mainly in real-time applications. Also does research in Intelligent Agents, Multiagent Systems and its Application for Modelling and Simulation, in problems related with Energy Efficiency and Smart Grid. He has coauthored more than 50 research papers and more than 70 presentations in conferences and symposia. He has directed more than 10 research projects and has been the advisor of 14 $\mathrm{PhD}$ Thesis. He has been reviewer of different conferences and scientific journals and has been also in the chair or organizing committee of four international conferences.

G. Dzemyda is a member of the Lithuanian Academy of Sciences, Professor, Director of the Institute of Informatics and Mathematics of Vilnius University and Head of the Systems Analysis Department of the institute. The research interests include visualization of multidimensional data, optimization theory and applications, data mining, multiple criteria decision support, neural networks, parallel computing, internet data mining, recommender systems, image analysis and medical informatics. The author of 223 research papers, two monographs and five textbooks.

O. Kurasova received the $\mathrm{PhD}$ in computer science from Institute of Mathematics and Informatics jointly with Vytautas Magnus University in 2005, Lithuania. Recent employment is at Institute of Mathematics and Informatics of Vilnius University, as senior researcher, and at the Informatics Department of Lithuanian University of Educational Sciences as associate professor. Her research interests include data mining methods, optimization theory and applications, artificial intelligence, neural networks, visualization of multidimensional data, multiple criteria decision making, multi-objective evolutionary algorithms parallel computing.

E. Kremers received his diploma in electrical engineering from Karlsruhe Institute for Technology, Germany in 2008. Since then he has been working as a researcher at the European Institute for Energy Research in Karlsruhe in the field of modelling and simulation 
of energy systems. In 2012 he received a PhD in Engineering from the Universidad del Pais Vasco, Spain. His main research focus is on agent-based modelling of complex energy systems, by developing integrative and bottom-up simulation approaches, based on geo-spatial modelling methods for Smart Grids and Smart Cities. Dr. Kremers is currently in charge of the Intelligent Energy System Team in EIFER.

\section{Spiečiaus intelektas dažniui valdyti išmaniuosiuose elektros tinkluose}

Jose EVORA, Jose Juan HERNANDEZ, Mario HERNANDEZ, Gintautas DZEMYDA, Olga KURASOVA, Enrique KREMERS

Elektros energijos tinklų saugumas ir jų kokybiškas funkcionavimas reikalauja dažnio valdymo, siekiant jo reikšmę išlaikyti stabilia - nedaug nutolusia nuo standartinės reikšmės $(50 \mathrm{~Hz})$. Dažnio nuokrypi nuo šios reikšmės įtakoja disbalansas tarp pagamintos ir sunaudotos energijos. Pagal išmaniujų elektros tinklų paradigmą, balansas gali būti pasiektas reguliuojant vartojimą priklausomai nuo elektros energijos gamybos galimybių. Šiame straipsnyje pasiūlytas spiečiaus intelektu pagrịstas metodas dažniui valdyti. Metodas remiasi idejja, kad spiečius yra sudarytas iš decentralizuotų pavienių agentų (dalelių) ir kiekvienas sąveikauja vienas su kitu per bendrą aplinką. Pasiūlytos trys spiečiaus intelektu pagrịstos strategijos užtikrina decentralizuotą dažnio valdymą išmaniuosiuose elektros tinkluose, kur spiečiaus agentai veikia ir priima sprendimus elektros vartojimo pusejje. Strategijos viena nuo kitos skiriasi agentų funkcijomis. Pasiūlytos strategijos yra palygintos eksperimentiškai. 